\title{
Communicating geoscience in uncertain times
}

\author{
In a meeting that discussed the \\ art and science of geoscience \\ communication, Hazel Gibson and \\ Jen Roberts report that the most \\ effective exchanges require \\ us to listen, and not just speak
}

Under the geoscience umbrella shelters a great breadth and depth of topics and concepts, from the applied to the abstract, and from the every-day to the extraordinary. This umbrella branches onto ethical and philosophical topics around the environment, society, justice, economics, heritage and so on-it is truly interdisciplinary. It is no wonder, then, that communicating geoscience can be tricky. Indeed, it is increasingly acknowledged that challenges in communicating geoscience are a major barrier to developing new geological technologies for society.

Many geoscientists will have witnessed or experienced times when the communication of controversial subjects caused turmoil, professionally and personally. Geoscientists worry about how to effectively communicate with various diverse stakeholders; how to 'get people onside' or seek 'permission' and 'support' to do their jobs, or simply be a geoscientist. This worry can turn to outright fear and trepidation when they see examples where communication is perceived to have gone badly, from either side of the argument.

A meeting at the Geological Society focused on exactly this issue of communication, from one of the fields that arguably experiences some of the most heated and emotionally charged conversations about development: Petroleum Geoscience. Organised by Kirstie Wright and Anna Clark from Heriot Watt University, the 'Communicating Geoscience: Building Public Interest and Promoting Inclusive Dialogue' conference (https:// www.geolsoc.org.uk/expired/PGCommunicating-Geoscience) on
September 4th was designed to be diverse, with speakers from industry, academia and NGO's from several countries sharing their experiences and advice. The discussions prompted participants to look beyond the gaps that separate us from our audiences and instead look for ways to connect with them.

\section{Building public interest}

The main themes from the day can be broken into two. The first, building public interest, was what many expect and rely on from conferences about geoscience communication; how do scientists reach beyond their own circle of colleagues to share their science with more diverse audiences? Particularly useful for those new to science communication, the talks covered topics such as: writing blogs; using Twitter, Instagram and other social media; creating video-blogs (vlogs) on YouTube; writing for popular media websites; and finding the story in your science.

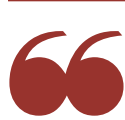

SCIENTISTS TEND TO ASSUME THAT IF ONLY THEY COULD COMMUNIICATE THE 'FACTS', THE AUDIENCE WOULD THEN THINK LIKE THEM

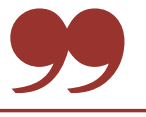

Several professional and academic scientists shared their experiences of communicating to non-expert audiences and gave valuable advice for those looking to participate in broadening communication to outreach, engagement and beyond. Stephanie Zihms advised delegates to 'diversify your reach and break stereotypes by sharing more than your professional geologist persona on social media', Laura Roberts suggested that scientists should 'tell stories about your science that are relevant to your audience, in the same way that the mainstream media does', Jan Freedman proposed to 'use networks to find others who want to communicate about geoscience like you do' since effective communication is easier to achieve with a team and John Underhill emphasised that we shouldn't be afraid to communicate, telling participants to 'seize your opportunity'.

\section{Promoting inclusive dialogue}

The second theme of the conference was something a little different, exploring the idea that geoscience communication goes beyond the effective transfer of information from scientist to audience. Speakers introduced the ideas of the co-production of geoscience communication, dialogue-based practice and the critical need to engage with social science issues for the continued development of our field. It was almost like the first theme was telling geoscientists how best to talk, and this second theme was telling geoscientists how best to listen.

Social anthropologist, Anna Szołucha, talked about public concerns regarding the potential environmental and social impacts of fracking, as part of her work on the ReFINE project, an international research consortium on fracking. Anna raised a crucial point, that public objections highlight other voices that should be considered-and included-when determining our shared future. This perspective was echoed by many speakers. In a room full of scientists, it was refreshing to dwell on the argument that objection

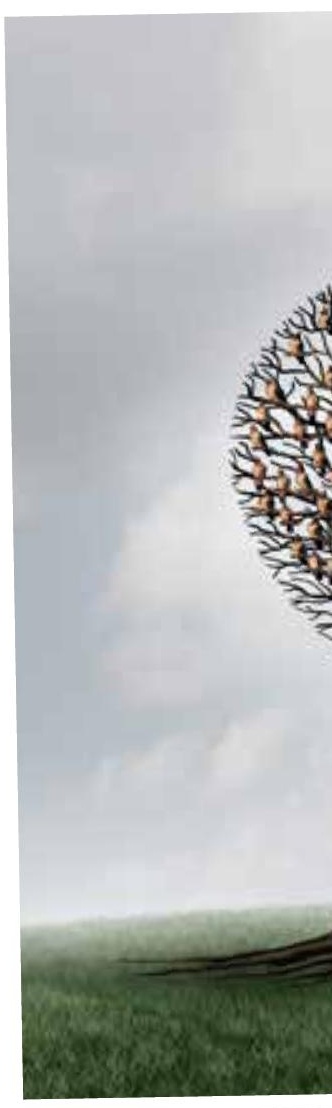


and controversy aren't merely a factor of bad communication. While poor communication can exacerbate controversy, scientists tend to assume that if only they could communicate the 'facts', the audience would then think like them.

We discussed how best to nurture dialogic communication and draw communities into the co-production of outreach and decision making, what facts and values are and to whom, what it means to gain 'consent' from communities, and whether and how our identities as geologists and our perspectives about our field influence our communication. By exploring these themes, attendees were encouraged to not only reach across the divide, but to move their goalposts to accommodate a range of stakeholder views and needs.

\section{Building geoscientists' interest}

The 'Communicating Geoscience' conference was an encouraging experience. Not only did the event deliver on its title-to build public interest and promote inclusive dialogue-it seemed to also build geoscientists' interest in communicating geoscience. There was an energy for challenging each other to look into the future to envisage where we are going with geoscience communication.

The whole day was live streamed online enabling participants (who would not have been able to take part in any other circumstances) to engage remotely. We commend organisers in the Petroleum Group and the Geological Society of London for this innovative step forward, which felt particularly relevant for this conference; communication only works if everyone is able to be a part of the conversation.

Dr Hazel Gibson is in the Sustainable Earth Institute, University of Plymouth; e-mail: hazel.gibson@ plymouth.ac.uk

Dr Jen Roberts is in the Department of Civil and

Environmental Engineering, University of Strathclyde; e-mail: jen.roberts@strath.ac.uk

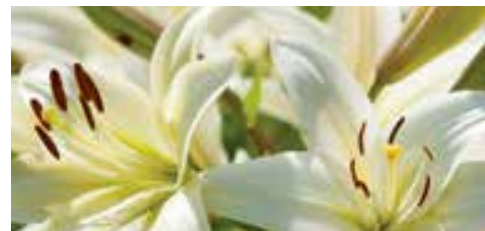

The Society notes with sadness the passing of:

Barnes, Barry *

Barnes, Simon James *

Booth, Tony *

Bowen, Geoffrey Gordon *

Carmichael, David

Casey, Raymond *

Cooke, Herbert Basil *

Dobson, Margaret *

Fletcher, Brian *

Gladwell, David Robert *

Ince, David Martyn *

Kenna, Raymond *

Lambert, John F*

Llewellyn, Peter L

Lynch, Edward *

Manning, Aubrey *

Matheson, William *

Milward, Anthony Frederick *

Moores, Eldridge *

Morgans, Michael William *\$

Okada, Hakuyu *

Pegg, Eric Arnold *

Roberts, Brinley

Shrimpton, Godfrey *

Smith, Howard James *

Thomson, Martyn Hugh *

Veevers, John James *

White, Owen *

In the interests of recording its Fellows' work for posterity, the Society publishes obituaries online, and in Geoscientist. The most recent additions to the list are in shown in bold. Fellows for whom no obituarist has yet been commissioned are marked with an asterisk (*). The symbol $\S$ indicates that biographical material has been lodged with the Society.

If you would like to contribute an obituary, please email amy.whitchurch@geolsoc. org.uk to be commissioned. You can read the guidance for authors at www. geolsoc.org.uk/obituaries. To save yourself unnecessary work, please do not write anything until you have received a commissioning letter.

Deceased Fellows for whom no obituary is forthcoming have their names and dates recorded in a Roll of Honour at www.geolsoc.org.uk/obituaries.

\section{Help your obituarist}

The Society operates a scheme for Fellows to deposit biographical material. The object is to assist obituarists by providing contacts, dates and other information, and thus ensure that Fellows' lives are accorded appropriate accurate commemoration. Please send your CV, publications list and a photograph to Amy Whitchurch at the Society. 